Research Article

\title{
The Influence of Enterprise Design Risk Attitude on the Choice of Heterogeneous Open Innovation Alliance
}

\author{
Changchun Sun $\mathbb{D},{ }^{1}$ Ruiyi Dong $\mathbb{D}^{1},{ }^{1}$ Yunsheng Xin $\mathbb{D}$, ${ }^{1}$ and Nina Su $\mathbb{C}^{2}$ \\ ${ }^{1}$ School of Mechanical Engineering, Taiyuan University of Science and Technology, Taiyuan 030024, China \\ ${ }^{2}$ College of Economics and Management, Taiyuan University of Technology, Taiyuan 030024, China \\ Correspondence should be addressed to Yunsheng Xin; xin_yunsheng@tyust.edu.cn
}

Received 29 May 2021; Revised 11 August 2021; Accepted 17 August 2021; Published 26 August 2021

Academic Editor: Muhammet Gul

Copyright $\odot 2021$ Changchun Sun et al. This is an open access article distributed under the Creative Commons Attribution License, which permits unrestricted use, distribution, and reproduction in any medium, provided the original work is properly cited.

\begin{abstract}
The choice of open innovation alliance has a significant impact on avoiding potential design risk. In order to reduce the enterprise design risk, an evaluation index system of innovation capability, including design risk, is constructed by considering the aspects of design risk identification, risk response, and risk monitoring. Then, a design risk evaluation method based on the prospect theory and fuzzy TOPSIS method is proposed. Combined with the prospect theory, the influences of three different risk attitudes (risktaking, intermediate, and conservative) on design decisions are analyzed. Finally, the evaluation system and method are applied to the design evaluation of digital welding power source, and its feasibility is verified by a numerical example. The results show that the conservative risk attitude is consistent with the closeness evaluation results, and the intermediate risk attitude is consistent with the risk-taking attitude evaluation results. Introducing the psychological risk factors of the subject into the design decisionmaking behavior can help enterprises to choose the innovation alliance, which is more in line with the actual needs and reduces the innovation risk to the greatest extent. The index system and evaluation method established in this paper can provide theoretical reference for enterprise design risk analysis.
\end{abstract}

\section{Introduction}

With the development of science and technology, the interdisciplinary application of multi-fields and disciplines is promoted, and individual enterprises are limited by their own scale and resource allocation. In innovation activities, they tend to seek the sharing of resources and knowledge from external resources (universities, scientific research institutions, or other enterprises), and take open innovation as the main way to improve the success rate of innovation, reduce the risk of innovation, and shorten the innovation cycle. The essence of open innovation, first proposed by Chesbrough [1], is to encourage enterprises to seek creative ideas internally and externally at the same time and to commercialize them successfully. It has now become a popular trend of collaborative design to choose a suitable design team and outsource all or part of product design, marketing operation, print or film advertising work to professional design teams in order to reduce costs and improve efficiency.

Design is not only a typical innovation activity but also has its unique characteristics. In terms of its connotation, it has the function of "arranging and planning in advance, and reflecting and completing something in a specific way." Moreover, it covers more contents because of its humanistic and aesthetic characteristics. In the past, product design was the duty-bound responsibility of the enterprise technology department and development department. With the development and progress of the industry, users' requirements for products have gradually improved, and product design is being gradually outsourced to specialized industrial design companies as service business content by industrial manufacturing enterprises. Design outsourcing is widely adopted at home and abroad, and the design service industry represented by professional design firms has mushroomed rapidly. The world's top 500 companies are increasingly 
relying on design outsourcing services to varying degrees. Design outsourcing refers to an enterprise that separates part of the business content and business process from the value chain and outsources it to an external professional design service provider to complete an economic activity, so that it can focus on the core business, reduce costs, improve efficiency, and enhance the enterprise's core competitiveness and environmental resilience. Design service outsourcing emphasizes high specialization and advocates full reliance on professional organizations and professionals. However, because the internal and external collaboration process involves multiparty $\mathrm{R} \& \mathrm{D}$ cooperation, it will enhance the instability of heterogeneous open innovation due to cultural background, organizational structure, target selection, and other factors. Even because of information asymmetry or asynchrony, different sharing ability, and other factors, the shadow of risk is laid for open innovation.

Therefore, although design outsourcing is conducive for the development of enterprises and the improvement of their product design capabilities, to a certain extent, enterprises need to control the quality of design outsourcing, carry out tracking management, and have a good understanding of the possible design risks. Design risk is also one of the potential risk inducements in enterprise product innovation. Innovation is often accompanied by the advent of new products and new technologies. Due to the lack of understanding of potential market users, there is a lag in the degree of market recognition and acceptance, and there is also a delay in the benefits of innovation. At the same time, there are also design risks that are delayed. In the process of design, due to the influence of subjective and objective factors, the actual achievement of the design deviates from the design goal, thus causing the loss of design value. Design risk will not only cause enterprises to suffer economic losses from the failure of new product development but also produce other potential adverse reactions. In serious cases, it will even cause users to suffer personal injury. The research of design risk should not only explore various potential economic losses in the design process from the perspective of enterprises but also take the position of decision-makers in order to reduce the impact of design risk to the minimum category.

The main purpose of this study is to track key decision points on the basis of previous work [2], classify decisionmakers' risk attitudes, and then study the risk assessment and management in the design and new product development. Enterprise risk attitude refers to the risk tolerance capacity of individual enterprises, including not only the ability to protect intellectual property rights but also the leader's risk preference, strategy selection, and organizational management, as well as the technology department's ability to avoid and respond to technological risks. The role of design in innovation is well known, but measuring the criteria for partner evaluation that include design risk is a complex task [3]. Most of the existing models have some limitations when considering the heterogeneity of partners. In this paper, different ways of innovation are taken as the main consideration for the selection of open innovation alliances, and different types of partners are selected, respectively. According to the advantages and disadvantages of their innovation ways, the ability evaluation system considering design risk is constructed. Considering the different preferences of decision-makers to risk attitudes, the fuzzy decision matrix is transformed into the prospect value matrix by using TOPSIS method based on prospect theory and fuzzy sets. The relative closeness degree is replaced by the calculated revenue loss ratio, the advantages and disadvantages of alternative schemes are ranked and verified with the example, and then the resistance ability and strain ability of different types of innovation alliances to innovation risks are evaluated.

\section{Literature Review}

2.1. Design Risk. Because of the interdisciplinary nature of new product development based on design, a preliminary assessment of the literature on design may be helpful to carry out new risk research. Design management risk integration is fundamentally different from the general design risk management. It mainly focuses on the risk integration at the strategic and operational levels, rather than the risk management at the control and reporting levels [4]. In 2005, the Cox Review [5], a research report submitted by the former chairman of the British Design Council to the government, proposed the important role of design in promoting emerging economies and the influence mechanism of design on the creativity of enterprises, and suggested that the UK could take its design industry as a breakthrough point for competition. Later, Clayton and Bookxs [6] considered the product design risks from the perspective of project management. He believed that design risk assessment is an activity to determine the potential risks in the design process, which includes two processes: conceptual design and detail design. Design risk assessment also requires the reduction of all kinds of possible failures and the consequent impact of failures, so as to detect and control the system-level risks as soon as possible. Khan et al. [7] used case studies to understand the role of product design in supply chain decisionmaking, especially in reducing supply chain risk and improving supply chain agility. They also emphasized that the product design process is a strategic tool to improve competitiveness and plays an important role in the development of global supply chain strategy. Jerrard et al. [8] pointed out that in the corporate structure (especially in small companies), the part of the designer does not have enough awareness of risks. When a risky design content is transmitted to decision-makers, it is easy for them to make wrong decisions due to the lack of professional judgment on design. Finally, the risk of design continues and results in the failure of new product development. Based on the concept of "Risk-taking in Design," Jerrard et al. [9] once again interviewed five small creative companies to investigate the way they perceive and evaluate design and risk in the process of new product development, and found that the perception of risk in each company varies greatly. This study provides a reflection on the practice of creative design, and also has potential significance for the formulation of business support policies. 
Due to the particularity of the design task and the repeatability of the design process, various aspects that may produce design risks are involved: the time span needed by the design enterprise and the capital conditions and hardware conditions of the experimental trial production; blindly pursuing the gorgeous effect on the design drawings will only lead to the continuous increase of costs, and there is a certain financial risk; the design company shall keep the design tasks of the main enterprise confidential to prevent the disclosure of any design tasks and design results before the product is launched; the design company shall be responsible for the design works, which must be original innovative design or imitation innovation that does not involve intellectual property rights, etc. Therefore, the decision-making subject enterprises have sufficient cognition of design risks at the early stage of screening, which is conducive for their own development and improvement of innovation efficiency.

2.2. Multicriteria Decision-Making Method. In the selection of decision-making methods, hundreds of models and algorithms have been applied to the multicriteria decisionmaking process $[10,11]$. Multicriteria decision-making (MCDM) is a complex and dynamic process that selects the best alternative solution by defining the ultimate goal. In this kind of decision-making process, the selection of innovative design company is not only based on the basic situation of the design company but also based on the subjective judgment of the decision-maker on the existing conditions and expected goals of the enterprise. MCDM can perform a multicriteria ranking of alternatives and assist the decision process by analyzing and listing the important properties of noninferior and/or compromise solutions. Since the 1970s, the research on the problem and method of multicriteria decision-making has become a hot topic in the academic circle. Scholars have carried out extensive theoretical and methodological research on multi-objective decision-making, statistical decision-making, sequential decision-making, and decision system. "Multiple attribute decision-making," the first research monograph on multicriteria decisionmaking, appeared in the 1980s, which summarized and sorted out theories, methods, and other achievements [12]. Since then, multicriteria decision-making methods have been developed rapidly, such as analytic hierarchy process (AHP) [13], multidimensional preference linear programming (LINMAP) [14], approach to ideal solution (TOPSIS) [15], compromise sorting (VIKOR) [16], and other widely used decision-making methods. Many scholars have also improved and expanded the process and application scope of these methods and proposed methods that can adapt to different decision-making environments.

Among them, analytic hierarchy process (AHP) is a measurement theory by pairwise comparison, which relies on the judgment of experts to derive the priority scale. Judgments may be inconsistent. How to measure the inconsistency and improve the judgment, so as to obtain better consistency when possible is the focus of AHP. On this basis, scholars have proposed many methods combined with AHP, such as grey relational degree, TOPSIS, and so on. TOPSIS (Technique for Order Preference by Similarity to an Ideal Solution) method was first proposed by Hwang and Yoon [17]. Its essential attribute is to judge the proximity of the target and evaluate the relative merits of the existing scheme by calculating the distance between the target and the best scheme and the worst scheme. Due to the complexity of decision-making problems and the limitation of enterprise cognition on the subject of decision-making [18], fuzzy TOPSIS is a common multi-objective decision-making method in the field of management science. Compared with the traditional evaluation method, fuzzy TOPSIS not only has the advantages of intuitive and convenient calculation, small demand for sample size, objective and reasonable analysis but also can more accurately reduce the impact of subjective factors of evaluation index on the results [19]. It can provide the value of positive and negative ideal solution for the development of prospect theory, which can be used as the evaluation standard of loss and profit. Both Vikor and TOPSIS are based on aggregate functions that indicate "near ideal" [20]. The VIKOR method can also provide reference points for the forward theory, but the ranking of VIKOR focuses more on the degree of proximity to the ideal solution, which may select the scheme with the best overall solution and the worst single solution to some extent. TOPSIS avoids this with two reference points.

In the decision-making of design enterprise selection, the main enterprise has made leap-forward progress through channels such as joint venture, introduction, cooperation, and independent innovation, while at the same time taking on additional risks caused by design outsourcing. Since the characteristics of partners have some subcriteria, the combination evaluation method is beneficial to comprehensively measure the development level and background of the enterprise, so this paper adopts the combined method of AHP and TOPSIS to construct a partner selection model considering design risks.

2.3. Prospect Theory. Kahneman and Tversky [21] put forward the prospect theory, which is based on psychology to improve the classical expected utility theory. Its premise is "bounded rationality," which is an important theory of behavioral decision-making. Prospect theory distinguishes the standard of subjective expectation from the value itself but makes behavioral decisions corresponding to the reference point of subjective choice.

Prospect value mainly includes value weight and weight function. The value function is the value of the decisionmaker's subjective feelings based on the actual benefits and losses. The value function proposed by Tversky is shown in the following equation (1):

$$
V(\Delta x)= \begin{cases}\Delta x^{\alpha}, & \Delta x \geq 0, \\ -\theta(-\Delta x)^{\beta}, & \Delta x<0 .\end{cases}
$$

Here, $\Delta x$ is the distance from the reference point, $\Delta x \geq 0$ is for profit, $\Delta x<0$ is for loss; $\alpha, \beta$ is the risk attitude coefficient; and $\theta$ is the risk attitude coefficient. By assigning 
values to $\alpha, \beta$, different risk attitudes of main enterprises can be reflected. Through the reproduction of Tversky's experiment, Zeng [22] found that the value of $\alpha, \beta$ for Chinese students could be greater than 1 with the same experimental procedure. The reason for this phenomenon is that the experimental data are not completely consistent with China's national conditions. Jian and Sun [23] believe that the difference is not caused by the difference between China and the United States, but that there is space for improvement in the value of parameters. Therefore, they put forward three different types of risk attitudes: adventurous $(0<\alpha, \beta<1)$, intermediate $(\alpha=\beta=1)$, and conservative $(\alpha, \beta>1)$. On the basis of this research, more scholars made discussions [24]. The prospect theoretical value functions of three different risk attitudes are shown in Figure 1. For risktaking decision-makers, risk aversion is adopted when they face gains, and risk preference is adopted when they face losses; however, the conservative decision-makers take risk preference for gains and risk aversion for losses.

Prospect theory reveals the influence of subconscious psychology on decision-making results and promotes the continuous improvement of decision-making theory. By introducing the prospect theory, this paper judges the risk attitude of the main enterprise in the decision-making process. Reference point is an important parameter to measure gain and loss, so selecting a reasonable reference point in prospect theory has an important influence on the decision-making result [25]. In this paper, we select the reference point of multi-attribute decision-making as the positive and negative ideal solution [26].

\section{Evaluation Index System of Technological Innovation Ability considering Risk}

The improvement of enterprise innovation ability must be based on the accurate evaluation of enterprise innovation ability. A sound index system can promote enterprises to find the deficiencies of their innovation ability through comprehensive and scientific evaluation, and provide them with a basis for decision-making, so as to maintain and improve the competitive advantage of innovation. Many scholars try to synthesize what criteria can be used in the selection of strategic partners. For example, in an earlier attempt, Brendel [27] first formulated a list of 20 key issues for reference to the selection criteria of potential members. Brouthers et al. [28] focused on four broad categories of factors, called "complementary skills," "cooperative culture," "compatible objectives," and "commensurate risk levels." According to Dacin et al. [29], some characteristics of strategic partner selection are post analysis of the motivation, criteria, practices, and results of the partner selection process. Chen et al. [30] combined the four periods of the technological change cycle model to discuss the motivation of enterprise alliance and the criteria of partner selection. $\mathrm{Wu}$ et al. [31] constructed the index system into five indicators including partner characteristics, marketing ability, intangible assets, management ability, and fitness and 19 subcriteria. Angeles and Nath [32] developed a 31-item questionnaire to study 6 cooperation factors, including

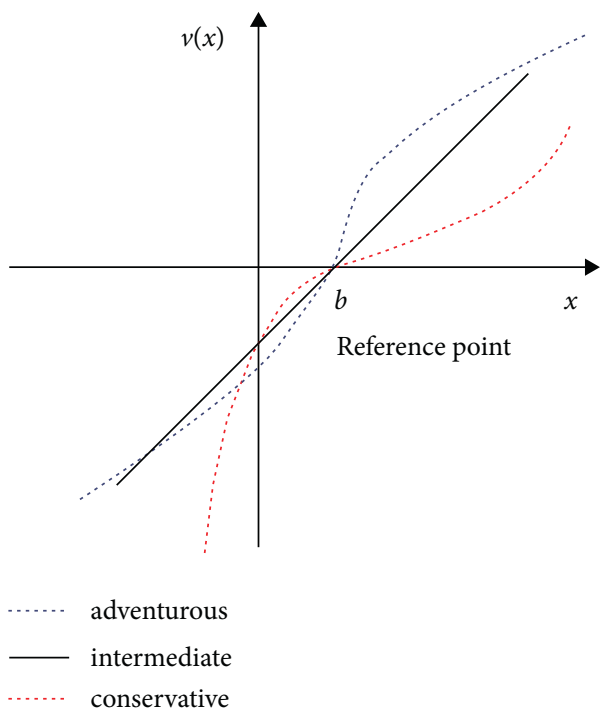

FIgURe 1: Prospect theoretical value function of three different risk attitudes.

strategic commitment, partner flexibility, infrastructure, communication, etc. Solesvik and Westhead [33] found that successful alliances are related to partners who establish trust and honesty, share common strategic goals, and provide relevant resources and capabilities. The basic principles of intercompany cooperation will change with the passage of time, and the motivation is related to the development stage.

Previous research on innovation or product design evaluation mainly focused on innovation capability and innovation performance, and the consideration of innovation risk or design risk was not systematic. Because of the factors such as large investment in the early stage of innovation activities, uncertain return period, and unstable innovation benefit, this paper effectively controls the main factors influencing technological innovation from the aspects of risk identification, risk response, and risk monitoring to scientifically reflect design risk. The construction of innovation capability evaluation model including design risk assessment is helpful to reduce the design risk and avoid the unnecessary loss. In the introduction of design risk, this paper combines interviews and actual research. Then, on the basis of referring to the existing design risk research system of domestic and foreign scholars, this paper mainly selects the anti-risk awareness of decision-makers, the risk aversion awareness, and adaptability of various departments to consider. The evaluation index system of innovation alliance considering open innovation risk is designed as 5 first-level indexes and 20 second-level indexes. The index system and data sources are shown in Table 1.

$\mathrm{R} \& \mathrm{D}$ expenditure intensity refers to the proportion of R\&D expenditure in innovation investment. Technical personnel input refers to the proportion of personnel engaged in technical research in the innovation team. To a certain extent, the two can reflect the R\&D investment of enterprises from the financial and human aspects. The implementation of new technology can accelerate the commercialization of collaborative innovation results, 
TABLE 1: Evaluation index system and data sources.

\begin{tabular}{|c|c|c|c|c|}
\hline Variable & Item & Code & Data sources & Literature sources \\
\hline \multirow{4}{*}{ ReD input capacity $\left(W_{1}\right)$} & R\&D funding intensity & $W_{11}$ & Statistical data & \multirow{4}{*}{$\begin{array}{c}\text { Angeles and Nath [32], Kor and Mesko } \\
\text { [34], Guan and Ma [35] }\end{array}$} \\
\hline & Technical personnel input & $W_{12}$ & Statistical data & \\
\hline & $\begin{array}{l}\text { Implementation intensity of new } \\
\text { process }\end{array}$ & $W_{13}$ & Expert rating & \\
\hline & Technology purchasing power & $W_{14}$ & $\begin{array}{l}\text { Comprehensive } \\
\text { analysis }\end{array}$ & \\
\hline \multirow{6}{*}{$\begin{array}{l}\text { Independent ReD } \\
\text { capability }\left(W_{2}\right)\end{array}$} & Amount of prior technology & $W_{21}$ & $\begin{array}{l}\text { Comprehensive } \\
\text { analysis }\end{array}$ & \multirow{6}{*}{$\begin{array}{l}\text { Brendel [27], Brouthers et al. [28], Dacin } \\
\text { et al. [29], Wu et al. [31], Helfat [36] }\end{array}$} \\
\hline & $\begin{array}{l}\text { Per capita quality of technical } \\
\text { personnel }\end{array}$ & $W_{22}$ & Statistical data & \\
\hline & Proportion of technical personnel & $W_{23}$ & Statistical data & \\
\hline & Experience of technical personnel & $W_{24}$ & Statistical data & \\
\hline & Innovation incentive mechanism & $W_{25}$ & $\begin{array}{l}\text { Comprehensive } \\
\text { analysis }\end{array}$ & \\
\hline & Proportion of independent design & $W_{26}$ & $\begin{array}{c}\text { Comprehensive } \\
\text { analysis }\end{array}$ & \\
\hline \multirow{4}{*}{$\begin{array}{l}\text { Organization and } \\
\text { management ability }\left(W_{3}\right)\end{array}$} & Leaders' willingness to innovate & $W_{31}$ & Expert rating & \multirow{4}{*}{$\begin{array}{c}\text { Angeles and Nath [32], Kor and Mesko } \\
\text { [34], Helfat et al. [36], Helfat and Peteraf } \\
\text { [37] }\end{array}$} \\
\hline & $\begin{array}{l}\text { Decision-making level innovation } \\
\text { risk prevention awareness }\end{array}$ & $W_{32}$ & Expert rating & \\
\hline & $\begin{array}{c}\text { Comprehensive quality of design } \\
\text { team }\end{array}$ & $W_{33}$ & Statistical data & \\
\hline & Design risk resilience & $W_{34}$ & Expert rating & \\
\hline \multirow{4}{*}{ Marketing capability $\left(W_{4}\right)$} & Market awareness of similar products & $W_{41}$ & Expert rating & \multirow{4}{*}{$\begin{array}{c}\text { Wu et al. [31], Guan and Ma [35], Tan [38], } \\
\text { Chau and Lin [39] }\end{array}$} \\
\hline & Marketing capability & $W_{42}$ & Statistical data & \\
\hline & Design and development cycle & $W_{43}$ & $\begin{array}{l}\text { Comprehensive } \\
\text { analysis }\end{array}$ & \\
\hline & E-business application capability & $W_{44}$ & Statistical data & \\
\hline Other indicators $\left(W_{5}\right)$ & $\begin{array}{l}\text { Intellectual property management } \\
\text { system } \\
\text { Macroenvironment of market launch } \\
\text { period }\end{array}$ & $W_{52}$ & $\begin{array}{l}\text { Comprehensive } \\
\text { analysis } \\
\text { Comprehensive } \\
\text { analysis }\end{array}$ & Wu et al. [31], Angeles and Nath [32] \\
\hline
\end{tabular}

shorten the R\&D cycle, and increase the investment cost. Therefore, the "new process implementation intensity" represents the promotion of the introduction of new manufacturing technology for the commercialization of R\&D achievements, which can indirectly reflect the acceptance of enterprises of new technologies. "Technology purchasing power" refers to the application ability of enterprises to obtain technology directly from external $R \& D$ teams to meet their own needs, which reflects the proportion of imported technology or patents and enterprises' independent $\mathrm{R} \& \mathrm{D}$ achievements. In the process of open innovation, enterprises with strong technology purchasing power can absorb mature technologies suitable for their own development through payment, which has stronger convenience and time advantage compared with independent research and development, which is difficult to tackle. But, technology purchase behavior has a certain dependence on external resources, which will increase the potential innovation risk caused by such factors as technology matching or technology reliability.

In terms of independent $\mathrm{R} \& \mathrm{D}$ capability, the "existing technology quantity" mainly indicates the achievements and technologies of enterprises' independent innovation before the development of open innovation, which can reflect the independent R\&D capability of main enterprises. Secondly, it mainly considers the relevant information of technical personnel, such as per capita quality, proportion of personnel, working experience, etc. In addition, the "innovation incentive policy" of enterprises to technical personnel is the main incentive to promote the enthusiasm of R\&D investment of technical personnel, and also the main means to promote the independent innovation ability of enterprises. Moreover, there is a potential $R \& D$ risk of overreliance on their own conditions for enterprises with independent innovation as the main body. The proportion of independent design can fully reflect the degree of fit between the technical team and the design department. Compared with commissioned design and other methods, independent design is conducive for the unity of design strategy, but it has a certain constraint on the divergence of product design thinking. The overall quality of organization and management team is also an important standard to measure the matching of enterprise innovation ability: The leader's willingness to innovate determines the initiative and enthusiasm of cooperation among enterprises; decisionmakers' awareness of innovation and prevention determines the sensitivity of enterprises to their own risks and external risks; the comprehensive quality of the design team determines the stability of the organization structure; design risk resilience will affect the timeliness of information transmission and the execution of decision-making. 
And, the marketing ability of innovation alliance is also one of the important references for selection [31]. When the two sides of the innovation alliance match the market cognition of similar products, it shows that both sides have a common voice in the technology field. The grasp of innovation $\mathrm{R} \& \mathrm{D}$ cycle of both sides can better supervise the consistency of the collaborative process, and lay a good foundation for the technology R\&D of both sides. In terms of marketing ability and e-commerce application ability, the main consideration is whether the two sides of the cooperation and alliance can learn from each other and reach a stable win-win situation. In addition, two aspects of intellectual property management system and the macro environment of the market launch period are selected from other technical indicators in order to avoid the situation of collective loss caused by the unilateral intellectual property loopholes of both sides of innovation, as well as the time-lag risk of technological innovation caused by changes in the market environment.

\section{Construction of the Evaluation Model of Technological Innovation Capability of Enterprises considering Risk}

4.1. Index Weight. In view of the fact that there are many indexes affecting the evaluation of enterprise's technological innovation capability and it is not easy to quantify, the AHP method is adopted to combine quantitative and qualitative methods. Firstly, the main indexes involved in the study (Table 1) are conceptualized, and the actual hierarchical structure is improved according to the potential association and subordination among the indexes; Secondly, the indexes of the same layer are compared in pairs from top to bottom, the judgment matrix among the factors of each layer is constructed by Delphi method and 1-9 scale method, the weight vector of evaluation index is obtained by using the square root method, and the weight set of the first-level evaluation index and the second grade rating index is obtained; Finally, in order to avoid the increase of errors caused by the subjectivity of experts in scoring, the consistency test is carried out on the judgment matrix.

\subsection{Evaluation Process of Fuzzy TOPSIS Based on Prospect Theory}

4.2.1. Construction of the Fuzzy Evaluation Set. When evaluating the high-tech scientific research projects, considering the fuzziness and subjectivity of each index, semantic judgment is used to express it. It can be divided into five levels: very low, low, average, high, and very high. The five semantic variables are represented by interval numbers, as shown in Table 2 .
TABLE 2: Linguistic values and interval numbers of innovation ability.

\begin{tabular}{lc}
\hline Semantic meaning of innovation ability & Interval numbers \\
\hline Very low (VL) & $(0,0.2)$ \\
Low (L) & $(0.2,0.4)$ \\
Average (M) & $(0.4,0.6)$ \\
High (H) & $(0.6,0.8)$ \\
Very high (VH) & $(0.8,1.0)$ \\
\hline
\end{tabular}

4.2.2. Construction of the Fuzzy Evaluation Matrix. According to the comment set, the initial fuzzy matrix of the second-level index is constructed as follows:

$$
\mathbf{X}=\left[\begin{array}{cccc}
x_{11} & x_{12} & \cdots & x_{1 j} \\
x_{21} & x_{22} & \cdots & x_{2 j} \\
\vdots & \vdots & \vdots & \vdots \\
x_{i 1} & x_{i 2} & \cdots & x_{i j}
\end{array}\right], \quad i=1,2, \ldots, p ; j=1,2, \ldots, q
$$

where $x_{p q}$ is the semantic value of the $q$-th second-level evaluation index of the $p$-th enterprise; $x_{p q}=\left(x_{p q}^{l}, x_{p q}^{u}\right)$

The normalization matrix $\boldsymbol{N}$ is obtained by standardizing the matrix $\boldsymbol{X}$.

$$
\mathbf{N}=\left[\begin{array}{cccc}
n_{11} & n_{12} & \cdots & n_{1 j} \\
n_{21} & n_{22} & \cdots & n_{2 j} \\
\vdots & \vdots & \vdots & \vdots \\
n_{i 1} & n_{i 2} & \cdots & n_{i j}
\end{array}\right], \quad i=1,2, \ldots, p ; j=1,2, \ldots, q .
$$

The four procedures are most well known in TOPSIS. These normalization procedures are (1) vector normalization, (2) linear scale transformation (Max-Min), (3) linear scale transformation (Max), and (4) linear scale transformation (Sum) [40]. The calculation method and characteristics are shown in Table 3.

By comparing the four calculation methods, it can be seen that vector enhancement has the advantage of converting all attributes into dimensionless measurement unit, thus making interattribute comparison easier. But, it has a drawback of having nonequal scale length leading to difficulties in straightforward comparison. Linear Scale Transformation (Max-Min) has the advantage that the scale measurement is precisely between 0 and 1 for each attribute, but the drawback is that the scale transformation is not proportional to outcome. Linear Scale Transformation (Max) and Linear Scale Transformation (SUM) can guarantee linear transformation of results. But Linear Scale Transformation (Max) can better reflect the contrast between elements, highlighting the advantages and disadvantages of the scheme. Therefore, in the normalization 
TABLE 3: Comparison of normalization methods and characteristics.

\begin{tabular}{|c|c|c|c|}
\hline \multirow[b]{2}{*}{ Method names } & \multicolumn{2}{|c|}{ Calculation method } & \multirow[b]{2}{*}{ Method characteristics } \\
\hline & $\begin{array}{l}\text { Benefit } \\
\text { attributes }\end{array}$ & Cost attributes & \\
\hline Vector normalization & $n_{i j}=\frac{x_{i j}}{\sqrt{\sum_{i=1}^{p} x_{i j}^{2}}}$ & $n_{i j}=\frac{1 / x_{i j}}{\sqrt{\sum_{i=1}^{p}\left(1 / x_{i j}^{2}\right)}}$ & $\begin{array}{l}\text { Converting all attributes into dimensionless measurement unit; } \\
\text { having nonequal scale length }\end{array}$ \\
\hline $\begin{array}{l}\text { Linear scale transformation } \\
(\max -\min )\end{array}$ & $n_{i j}=\frac{x_{i j}-x_{j}^{\min }}{x_{j}^{\max }-x_{j}^{\min }}$ & $n_{i j}=\frac{x_{j}^{\max }-x_{i j}}{x_{j}^{\max }-x_{j}^{\min }}$ & The scale transformation is not proportional to outcome \\
\hline $\begin{array}{l}\text { Linear scale transformation } \\
(\max )\end{array}$ & $n_{i j}=\frac{x_{i j}}{x_{j}^{\max }}$ & $n_{i j}=1-\frac{x_{i j}}{x_{j}^{\max }}$ & Outcomes are transformed in a linear way \\
\hline $\begin{array}{l}\text { Linear scale transformation } \\
\text { (sum) }\end{array}$ & $n_{i j}=\frac{x_{i j}}{\sum_{i=1}^{p} x_{i j}}$ & $n_{i j}=\frac{1 / x_{i j}}{\sum_{i=1}^{p} 1 / x_{i j}}$ & The sum of index elements is one \\
\hline
\end{tabular}

process of fuzzy matrices, Linear Scale Transformation (Max) is selected. The calculation method of elements in equation (3) is shown in the following equation:

$$
n_{i j}=\frac{x_{i j}}{\max \left(\max \left(x_{i 1}^{l}, x_{i 1}^{u}\right), \max \left(x_{i 2}^{l}, x_{i 2}^{u}\right), \ldots, \max \left(x_{i q}^{l}, x_{i q}^{u}\right)\right)}, \quad i=1,2, \ldots, p ; j=1,2, \ldots, q .
$$

Combined with the weight vector $\omega_{j}^{*}$ of evaluation index and the standardized matrix $\mathbf{N}$, the weighted interval standardized fuzzy matrix $\mathbf{Z}$ can be obtained as follows:

$$
\mathbf{Z}=\left[\begin{array}{cccc}
z_{11} & z_{12} & \cdots & z_{1 j} \\
z_{21} & z_{22} & \cdots & z_{2 j} \\
\vdots & \vdots & \vdots & \vdots \\
z_{i 1} & z_{i 2} & \cdots & z_{i j}
\end{array}\right]_{p \times q}, \quad i=1,2, \ldots, p ; j=1,2, \ldots, q
$$

where $z_{i j}=n_{i j} \times \omega_{j}^{*}$

\subsubsection{Calculation of the Positive and Negative Ideal Solutions.} TOPSIS is a user-friendly method that requires few inputs from the user [41]. It consists of choosing the alternative which is closest to the best solution, called the positive ideal solution, and furthest from the worst solution, called the negative ideal solution. The selection of ideal solution usually includes three modes [42]. As in the crisp version, different interpretations of ideal solutions exist. They can be classified into three main categories [43]:

(1) Absolute values: $\widetilde{v}_{j}^{+}=(1,1,1)$ and $\widetilde{v}_{j}^{-}=(0,0,0)[15]$

(2) Max-min values: $\widetilde{v}_{j}^{+}=\max _{i} \widetilde{v}_{i j}$ and $\widetilde{v}_{j}^{-}=\min _{i} \widetilde{v}_{i j}$ [44]

(3) Fixed values, as in the crisp version [45, 46]: for example, a combination of both [47], which produces the positive ideal solution $\tilde{v}_{j}^{+}=(1,1,1)$, and the negative ideal solution $\widetilde{v}_{j}^{-}=\min _{i} \widetilde{v}_{i j}$

By comparing the calculation methods of the above three ideal solutions, it can be seen that max-min values are calculated according to the elements in the decision matrix, and the selection of positive and negative ideal solutions is based on the evaluation matrix of the scheme. Compared with the other two methods, the method of selecting the ideal solution is closer to the result of the evaluation matrix. The core of this paper includes the design risk attitude, and the calculation method of max-min values' ideal solution can fully reflect the comparative relationship between the different attitudes of decision-makers, so as to make the results close to the actual situation and ensure the scientificity of the results.

The most commonly used ones are absolute and maxmin values. However rank reversal probably will remain an important tool for judging the validity of a multi-attribute decision-making method. According to Aires and Ferreira $[48,49]$, when the max-min values ideal solution was selected, TOPSIS did not present any rank reversal due to this cause in their studied examples. In general, among the three ideal solution modes, max-min values have the best stability. Therefore, the ideal solution mode of max-min values is selected in the design risk assessment in this paper.

The fuzzy positive ideal solution $Z^{+}$and negative ideal solution $Z^{-}$are the sets of maximum and minimum evaluation values in each index, respectively. The calculation method is as follows:

$$
\begin{aligned}
& Z^{+}=\left\{z_{j}^{+l}, z_{j}^{+u}\right\}=\left\{\left\{\max _{i} z_{i j} \mid j \in J_{1}\right\},\left\{\min _{i} z_{i j} \mid j \in J_{2}\right\}\right\}, \\
& Z^{-}=\left\{z_{j}^{-l}, z_{j}^{-u}\right\}=\left\{\left\{\min _{i} z_{i j} \mid j \in J_{1}\right\},\left\{\max _{i} z_{i j} \mid j \in J_{2}\right\}\right\},
\end{aligned}
$$

where $i=1,2, \ldots, p ; j=1,2, \ldots, q ; J_{1}$ is the benefit index; and $J_{2}$ is the cost index.

4.2.4. Calculation of the Index Closeness Degree. In heterogeneous multi-attribute decision-making, the closeness degree is usually used to reflect the closeness degree of 
TABLE 4: Calculation methods of distance between evaluation scheme and ideal solution.

\begin{tabular}{lcc}
\hline Distance metrics & $d_{i}^{+}$definition & $d_{i}^{-}$definition \\
\hline Euclidean & $d_{i}^{+}=\sqrt{\sum_{j=1}^{q}\left(z_{i j}-z_{j}^{+}\right)^{2}}$ & $d_{i}^{-}=\sqrt{\sum_{j=1}^{q}\left(z_{i j}-z_{j}^{-}\right)^{2}}$ \\
Manhattan & $d_{i}^{+}=\sum_{j=1}^{q}\left|z_{i j}-z_{j}^{+}\right|$ & $d_{i}^{-}=\sum_{j=1}^{q}\left|z_{i j}-z_{j}^{-}\right|$ \\
Lorentzian & $d_{i}^{+}=\sum_{j=1}^{q} \ln \left(1+\left|z_{i j}-z_{j}^{+}\right|\right)$ & $d_{i}^{-}=\sum_{j=1}^{q} \ln \left(1+\left|z_{i j}-z_{j}^{-}\right|\right)$ \\
Jaccard & $d_{i}^{+}=\frac{\sum_{j=1}^{q}\left(z_{i j}-z_{j}^{+}\right)^{2}}{\sum_{j=1}^{q}\left(z_{i j}+z_{j}^{+}\right)^{2}-z_{i j} z_{j}^{+}}$ & $\sum_{j=1}^{q}\left(z_{i j}-z_{j}^{-}\right)^{2}$ \\
Dice & $d_{i}^{+}=\frac{\sum_{j=1}^{q}\left(z_{i j}-z_{j}^{+}\right)^{2}}{\sum_{j=1}^{q} z_{i j}^{2}+\sum_{j=1}^{q}\left(z_{j}^{+}\right)^{2}}$ & $\left.d_{i}^{-}+z_{j}^{-}\right)^{2}-z_{i j} z_{j}^{-}$ \\
\hline
\end{tabular}

decision-making schemes. The positive and negative ideal solutions of heterogeneous information are calculated for comparison between schemes. Before calculating the index closeness degree, it is necessary to determine the distance $d_{i}^{+}$ and $d_{i}^{-}$between the evaluation scheme of innovation capability of each enterprise and the positive and negative ideal solutions. In the TOPSIS method, literature [42] conducted case analysis and found that the evaluation results of the five commonly used distance calculation methods are stable. The calculation methods are shown in Table 4.

The five distance calculation methods have their own characteristics. Compared with the five methods, it can be seen that the Euclidean distance and Manhattan distance calculation methods are simple. So, the distance between the evaluation scheme and the ideal solution can be calculated more concisely and directly, which meets the evaluation requirements of the technical innovation ability considering the risk index system. Manhattan distance seems good for high-dimensional data, but it is not as intuitive as Euclidean distance. Moreover, it is easier to give a higher distance value than Euclidean distance because it cannot be the shortest path. Euclidean distance can be understood as the length of the line segment connecting two points. Although Euclidean distance will deviate due to the unit change of features, this deficiency can be effectively solved after data normalization. To sum up, the matrix dimension studied in this paper is relatively small, so it is more appropriate to choose Euclidean distance for calculation in this paper. Therefore, the calculation method is as follows [50]:

$$
d_{i}^{+}=\sqrt{\sum_{j=1}^{q}\left(z_{i j}-z_{j}^{+}\right)^{2}}, \quad i=1,2, \ldots, p ; j=1,2, \ldots, q,
$$

$$
d_{i}^{-}=\sqrt{\sum_{j=1}^{q}\left(z_{i j}-z_{j}^{-}\right)^{2}}, \quad i=1,2, \ldots, p ; j=1,2, \ldots, q .
$$

The calculation method of index closeness degree is shown in equation (9). The index closeness degree can be calculated by combining equations (7)-(9). The higher the degree of closeness is, the stronger the enterprise's technological innovation ability is

$$
T_{i}^{*}=\frac{d_{i}^{-}}{d_{i}^{+}+d_{i}^{-}}, \quad i=1,2, \ldots, p
$$

4.2.5. Calculation of the Benefit-Loss Ratio for Each Scheme. Traditional decision-making methods are mostly based on expected utility theory, while in terms of behavior, risky decision-making largely depends on whether the decision-maker pays attention to profit or loss. According to the certainty and reflexivity of prospect theory, people are averse to risk before gain and prefer risk before loss. The unified reference mode is adopted in the calculation of the closeness degree, and the subjective tendency of the decision-maker is not integrated into the decision-making process. The ranking of the scheme according to the lossprofit ratio under the guidance of the prospect theory is helpful for the decision-maker to judge the bearing capacity of the design risk according to their own actual needs. According to the significance of value function in the prospect theory, it can be seen that: When the reference point of the positive ideal solution is selected, each scheme is a loss of value relative to the positive ideal solution; when the negative ideal solution is taken as the reference point, each scheme is a gain of value relative to the negative ideal solution. The calculation methods of profit loss and gain are shown in

$$
\begin{aligned}
& {\left[V_{i j}^{-}\left(d_{i}^{+}\right)\right]=\left[-\theta\left(d_{E}\left(z_{i j}, z_{j}^{+}\right)\right)^{\beta}\right]_{p \times q},} \\
& {\left[V_{i j}^{+}\left(d_{i}^{-}\right)\right]=\left[\left(d_{E}\left(z_{i j}, z_{j}^{-}\right)\right)^{\alpha}\right]_{p \times q^{\prime}}}
\end{aligned}
$$

where $\alpha, \beta$, and $\theta$ are known coefficients of the main enterprise, respectively; $\alpha$ is the risk avoidance coefficient, which indicates the risk aversion degree of the possible income when the main enterprise chooses the innovation alliance; $\beta$ is the risk preference coefficient, which represents the risk preference degree of the main enterprises facing unknown losses when they choose innovation alliance; and $\theta$ is the sensitivity of decision-makers of main enterprises to gains and losses, namely, the risk attitude coefficient. Finally, the loss-gain ratio of each scheme can be calculated according to the formula. The bigger the loss-gain ratio is, the better the scheme will be, so as to rank the schemes. 


$$
S_{i}=\frac{\left|\sum_{j=1}^{p} V_{i j}^{+}\left(d_{i}^{-}\right)\right|}{\left|\sum_{j=1}^{p} V_{i j}^{-}\left(d_{i}^{+}\right)\right|} .
$$

\section{Example Analysis}

Six experts were invited to evaluate the innovation ability of small and medium-sized science and technology enterprises in high-tech zones of Shanxi Province, and the evaluation was carried out through the evaluation system established above. After scoring the relative importance of the evaluation indicators, the experts calculated the weights of the first- and second-level indicators, as shown in Table 5. And, the consistency of the evaluation results was tested, and the evaluation results met the evaluation consistency. Suppose that the main enterprise is faced with the construction of new projects through collaborative innovation with four enterprises A, B, C, and D. Since the project involves the $\mathrm{R} \& \mathrm{D}$ and application of new products or new technologies, there is no precedent for reference. In order to effectively avoid innovation risks, combined with the advantages of the four enterprises and referring to the methods proposed in the previous paper, the innovation alliance suitable for the main enterprises is selected. According to the current situation of the four enterprises, the fuzzy evaluation set is obtained by means of expert evaluation, questionnaire survey, and interview analysis, as shown in Table 5.

Based on Table 5, the matrix of the secondary evaluation indexes of four enterprises (A, B, C, and D) is established according to formulas (2)-(5). The evaluation results are normalized by combining the first-level and second-level weights obtained by experts. The results of normalization are shown in Table 6.

Relative to the positive ideal solution in the TOPSIS method, the result of choosing any innovation alliance is loss, while it is gain relative to the negative ideal solution. In this paper, we use the value function parameters of decisionmakers with three different types of risk attitude [23], and risk-taking type $(\alpha=\beta=0.88)$, intermediate type $(\alpha=\beta=1)$, and conservative type $(\alpha=\beta=1.21)$ are selected, respectively. When $\theta=2.25$, the positive and negative ideal solutions of the normalized matrix are calculated according to Equations (5) and (6). Calculate the Euclidean distance by equations (7) and (8). Finally, the prospect decision value can be obtained according to Equations (10)-(11). The approximation degree of evaluation index is calculated according to Equation (9) for the calculation results of each enterprise, and the profit-loss ratio of the four enterprises is calculated according to Equation (12). The calculation results of closeness degree and profit-loss ratio and the ranking of innovation ability of four enterprises considering risk attitude are shown in Table 7 .

\section{Results and Discussion}

It can be seen from the scheme income ratio in Table 7 that the greater the income ratio, the stronger the advantage of choosing the innovation alliance. When the risk attitude of enterprises is considered as risk-taking and intermediate, the ranking result is $\mathrm{A}>\mathrm{C}>\mathrm{D}>\mathrm{B}$. Therefore, the results show that choosing enterprise $A$ as the innovation alliance has the best RD efficiency, which can make the best use of the advantages of both sides to promote the industrialization of open innovation achievements. When the enterprise risk attitude is conservative, the ranking result is $\mathrm{A}>\mathrm{C}>\mathrm{B}>\mathrm{D}$, and this result is consistent with the evaluation result of closeness degree. Although the best solution is enterprise A, the order of advantages and disadvantages of enterprise $B$ and D is slightly different. Meanwhile, by comparing the closeness degree, the decision order is the same as that of conservative enterprises. It can be seen from this that the model obtained under the traditional expected utility theory ignores the different risk attitudes of decision-makers facing gains and losses, only conforms to the conservative enterprises, and fails to consider the actual situation of enterprises with intermediate risk attitudes and risk-taking attitudes. However, considering the risk attitude of the decision-maker enterprise with the prospect theory is more in line with the actual decision-making needs.

Taking the design of digital welding power source as an example. In the initial stage of product design, a pulse welding power supply developed and designed by a company in Beijing involves product image identification design. After bidding, 4 design companies that meet the requirements of product design are selected. By referring to their tender, company background, expert evaluation, and other information, the design companies are screened according to the process mentioned above. The digital welding power supply has three independent welding modes: pulse gas shielded welding, direct current gas shielded welding, and flux-coated electrode manual welding (including simple argon arc welding), which can be selected according to different welding requirements. It mainly includes welding cable positive and negative connection seat, LCD display window, handle, adjusting knob, wire feeder interface, power supply nameplate, various types of selection interface, etc.

In the process of partner selection of enterprise serialized product research and development, according to the evaluation system of technology innovation ability considering design risk, the candidate enterprises are evaluated by expert evaluation. The selection of design companies was completed through multicriteria decision-making. According to the intermediate risk attitude, the design companies with certain design foundation and trial production conditions led by the design teachers of a university were selected. In the actual operation process, the pulse welding power supply research and development enterprise analyzed its own scale and customer group and found that the enterprise's own risk tolerance is weak. But, they have a strong desire for design change. By evaluating the risk attitude of the decision-making subject enterprise, the optimal partner of intermediate risk attitude is finally selected. The actual design effect of the project is shown in Figure 2.

During the collaborative innovation project, due to the uncertainty of open innovation and the time-lag of 
TABLE 5: Importance of expert evaluation and fuzzy evaluation set of enterprises.

\begin{tabular}{|c|c|c|c|c|c|c|c|}
\hline First-level indicators & Weight & Secondary indicators & Weight & Enterprise A & Enterprise B & Enterprise C & Enterprise D \\
\hline \multirow{4}{*}{$W_{1}$} & \multirow{4}{*}{0.308} & $W_{11}$ & 0.128 & $(0.6,0.8)$ & $(0.8,1.0)$ & $(0.6,0.8)$ & $(0.4,0.6)$ \\
\hline & & $W_{12}$ & 0.069 & $(0.8,1.0)$ & $(0.2,0.4)$ & $(0.4,0.6)$ & $(0.6,0.8)$ \\
\hline & & $W_{13}$ & 0.050 & $(0.4,0.6)$ & $(0.6,0.8)$ & $(0.6,0.8)$ & $(0.2,0.4)$ \\
\hline & & $W_{14}$ & 0.061 & $(0.4,0.6)$ & $(0.8,1.0)$ & $(0.6,0.8)$ & $(0.4,0.6)$ \\
\hline \multirow{6}{*}{$W_{21}$} & \multirow{6}{*}{0.277} & $W_{21}$ & 0.055 & $(0.6,0.8)$ & $(0.2,0.4)$ & $(0.4,0.6)$ & $(0.6,0.8)$ \\
\hline & & $W_{22}$ & 0.056 & $(0.6,0.8)$ & $(0.6,0.8)$ & $(0.6,0.8)$ & $(0.8,1.0)$ \\
\hline & & $W_{23}$ & 0.040 & $(0.8,1.0)$ & $(0.4,0.6)$ & $(0.6,0.8)$ & $(0.4,0.6)$ \\
\hline & & $W_{24}$ & 0.049 & $(0.6,0.8)$ & $(0.2,0.4)$ & $(0.4,0.6)$ & $(0.2,0.4)$ \\
\hline & & $W_{25}$ & 0.050 & $(0.8,1.0)$ & $(0.4,0.6)$ & $(0.8,1.0)$ & $(0.6,0.8)$ \\
\hline & & $W_{26}$ & 0.027 & $(0.2,0.4)$ & $(0.6,0.8)$ & $(0.2,0.4)$ & $(0.8,1.0)$ \\
\hline \multirow{4}{*}{$W_{3}$} & \multirow{4}{*}{0.179} & $W_{31}$ & 0.064 & $(0.8,1.0)$ & $(0.4,0.6)$ & $(0.4,0.6)$ & $(0.6,0.8)$ \\
\hline & & $W_{32}$ & 0.043 & $(0.2,0.4)$ & $(0.8,1.0)$ & $(0.6,0.8)$ & $(0.8,1.0)$ \\
\hline & & $W_{33}$ & 0.042 & $(0.4,0.6)$ & $(0.6,0.8)$ & $(0.4,0.6)$ & $(0.6,0.8)$ \\
\hline & & $W_{34}$ & 0.030 & $(0.4,0.6)$ & $(0.2,0.4)$ & $(0.6,0.8)$ & $(0.8,1.0)$ \\
\hline \multirow{4}{*}{$W_{4}$} & \multirow{4}{*}{0.134} & $W_{41}$ & 0.051 & $(0.6,0.8)$ & $(0.8,1.0)$ & $(0.8,1.0)$ & $(0.4,0.6)$ \\
\hline & & $W_{42}$ & 0.036 & $(0.2,0.4)$ & $(0.4,0.6)$ & $(0.8,1.0)$ & $(0.4,0.6)$ \\
\hline & & $W_{43}$ & 0.019 & $(0.8,1.0)$ & $(0.2,0.4)$ & $(0.4,0.6)$ & $(0.6,0.8)$ \\
\hline & & $W_{44}$ & 0.028 & $(0,0.2)$ & $(0.6,0.8)$ & $(0.8,1.0)$ & $(0.8,1.0)$ \\
\hline \multirow{2}{*}{$W_{5}$} & \multirow{2}{*}{0.102} & $W_{51}$ & 0.054 & $(0.6,0.8)$ & $(0.4,0.6)$ & $(0.2,0.4)$ & $(0.6,0.8)$ \\
\hline & & $W_{52}$ & 0.048 & $(0.4,0.6)$ & $(0.4,0.6)$ & $(0.6,0.8)$ & $(0.2,0.4)$ \\
\hline
\end{tabular}

TABLE 6: Normalized evaluation results of enterprise indicators.

\begin{tabular}{lcccc}
\hline Secondary indicators & Enterprise A & Enterprise B & Enterprise C & Enterprise D \\
\hline$W_{11}$ & $(0.0766,0.1021)$ & $(0.1021,0.1276)$ & $(0.0766,0.1021)$ & $(0.051,0.0766)$ \\
$W_{12}$ & $(0.0555,0.0694)$ & $(0.0139,0.0278)$ & $(0.0278,0.0416)$ & $(0.0416,0.0555)$ \\
$W_{13}$ & $(0.0249,0.0373)$ & $(0.0373,0.0497)$ & $(0.0373,0.0497)$ & $(0.0124,0.0249)$ \\
$W_{14}$ & $(0.0244,0.0366)$ & $(0.0488,0.061)$ & $(0.0366,0.0488)$ & $(0.0244,0.0366)$ \\
$W_{21}$ & $(0.0414,0.0552)$ & $(0.0138,0.0276)$ & $(0.0276,0.0414)$ & $(0.0414,0.0552)$ \\
$W_{22}$ & $(0.0335,0.0447)$ & $(0.0335,0.0447)$ & $(0.0335,0.0447)$ & $(0.0447,0.0559)$ \\
$W_{23}$ & $(0.0322,0.0403)$ & $(0.0161,0.0242)$ & $(0.0242,0.0322)$ & $(0.0161,0.0242)$ \\
$W_{24}$ & $(0.0369,0.0491)$ & $(0.0123,0.0246)$ & $(0.0246,0.0369)$ & $(0.0123,0.0246)$ \\
$W_{25}$ & $(0.0399,0.0499)$ & $(0.02,0.0299)$ & $(0.0399,0.0499)$ & $(0.0299,0.0399)$ \\
$W_{26}$ & $(0.0053,0.0106)$ & $(0.0159,0.0212)$ & $(0.0053,0.0106)$ & $(0.0212,0.0266)$ \\
$W_{31}$ & $(0.0511,0.0638)$ & $(0.0255,0.0383)$ & $(0.0255,0.0383)$ & $(0.0383,0.0511)$ \\
$W_{32}$ & $(0.0086,0.0172)$ & $(0.0345,0.0431)$ & $(0.0259,0.0345)$ & $(0.0345,0.0431)$ \\
$W_{33}$ & $(0.0211,0.0316)$ & $(0.0316,0.0422)$ & $(0.0211,0.0316)$ & $(0.0316,0.0422)$ \\
$W_{34}$ & $(0.0119,0.0179)$ & $(0.006,0.0119)$ & $(0.0179,0.0239)$ & $(0.0239,0.0299)$ \\
$W_{41}$ & $(0.0308,0.0411)$ & $(0.0411,0.0514)$ & $(0.0411,0.0514)$ & $(0.0205,0.0308)$ \\
$W_{42}$ & $(0.0072,0.0144)$ & $(0.0144,0.0217)$ & $(0.0289,0.0361)$ & $(0.0144,0.0217)$ \\
$W_{43}$ & $(0.0149,0.0187)$ & $(0.0037,0.0075)$ & $(0.0075,0.0112)$ & $(0.0112,0.0149)$ \\
$W_{44}$ & $(0,0.0057)$ & $(0.017,0.0227)$ & $(0.0227,0.0283)$ & $(0.0227,0.0283)$ \\
$W_{51}$ & $(0.0402,0.0536)$ & $(0.0268,0.0402)$ & $(0.0134,0.0268)$ & $(0.0402,0.0536)$ \\
$W_{52}$ & $(0.0241,0.0362)$ & $(0.0241,0.0362)$ & $(0.0362,0.0483)$ & $(0.0121,0.0241)$ \\
\hline
\end{tabular}

TABLE 7: Proportion of scheme income and loss.

\begin{tabular}{lccccc}
\hline & & Enterprise A & Enterprise B & Enterprise C & Enterprise D \\
\hline Closeness degree & & 0.5594 & 0.5049 & 0.5241 & 0.4599 \\
& Risk-taking type & 0.5510 & 0.3861 & 0.5255 & 0.4232 \\
Profit-loss ratio & Intermediate type & 0.5645 & 0.3921 & 0.5301 & 0.4135 \\
& Conservative type & 0.5905 & 0.4036 & 0.5365 & 0.3958 \\
\hline
\end{tabular}

product design innovation benefits, the risk attitude of enterprises has a significant impact on the selection of cooperative alliance. By analyzing the ability of alliances to avoid innovation risks, enterprises can choose more specific innovation alliances. And, according to their resistance to risk, the input-output ratio of collaborative process is balanced to better optimize the allocation of innovation resources. 


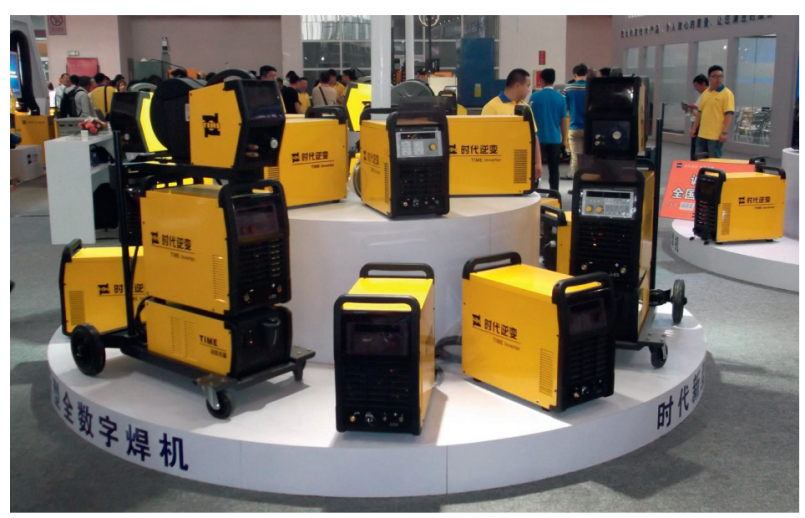

FIgURE 2: Actual product renderings.

\section{Conclusion}

Although technological innovation is a risky activity, it is also an effective way for enterprises to realize their own interests. Choosing the innovation alliance that can learn from each other is an effective means to improve the success rate of innovation and promote the commercialization of technology industrialization. By constructing an open innovation capability system considering risk aversion, this paper puts forward the evaluation method based on prospect theory and fuzzy TOPSIS evaluation method, which helps the main enterprises to choose their own innovation alliance under the risk attitude; truly; effectively; and scientifically carry out risk management; minimize the possibility of risk occurrence; and make technological innovation activities have higher value. Introducing the psychological risk factors of the subject into the design decision-making behavior can help enterprises to choose the innovation alliance which is more in line with the actual needs and reduce the innovation risk to the greatest extent.

\section{Data Availability}

The data used to support the findings of this study are included within the article.

\section{Conflicts of Interest}

The authors declare that there are no conflicts of interest.

\section{Acknowledgments}

This work was sponsored by the Fund for Shanxi " 1331 Project" Key Subject Construction, Shanxi Science and Technology Platform Project (201805D121005), Shanxi Province Science and Technology Major Project (20181102002), Taiyuan University of Science and Technology Scientific Research Initial Funding (20182037), Doctor Excellent Award Fund for Work in Shanxi (20192018), Higher Education Technology Innovation Project of Shanxi Province, Scientific and Technological Innovation Programs of Higher Education Institutions in Shanxi (2019L0649), and Applied Basic Research Project of Shanxi Province (201901D211288).

\section{References}

[1] H. W. Chesbrough, Open Innovation: The New Imperative for Creating and Profiting from Technology, pp. 43-62, Harvard Business School Press, Boston, MA, USA, 2003.

[2] B. Jerrard, R. Newport, and Trueman, "Managing new product innovation," Infant Behavior and Development, vol. 7, no. 2, p. 393, 2003.

[3] P. G. Radici Fraga, M. M. E. S. Bernardes, D. R. Vieira, and M. C. Chain, "Implementation issues of a design management indicator system," International Journal of Productivity and Performance Management, vol. 67, no. 5, pp. 890-915, 2018.

[4] T. J. Andersen, "The performance relationship of effective risk management: exploring the firm-specific investment rationale," Long Range Planning, vol. 41, no. 2, pp. 155-176, 2008.

[5] G. Cox, Cox Review of Creativity in Business: Building on the UK's Strengths, European Commission, Brussels, Belgium, 2005.

[6] M. Clayton and I. Booksx, "Risk happens!: managing risk and avoiding failure in business projects," in Proceedings of the International Conference on Green Circuits \& Systems, IEEE, Shanghai, China, June 2010.

[7] O. Khan, M. Christopher, and B. Burnes, "The impact of product design on supply chain risk: a case study," International Journal of Physical Distribution \& Logistics Management, vol. 38, no. 5-6, pp. 412-432, 2008.

[8] B. Jerrard, N. Barnes, and A. Reid, "Researching creative companies: lessons learned from a risk in design project," Creative Industries Journal, vol. 2, no. 2, pp. 161-178, 2009.

[9] R. N. Jerrard, N. Barnes, and A. Reid, "Design, risk and new product development in five small creative companies," International Journal of Design, vol. 2, no. 1, pp. 21-30, 2008.

[10] Y. Dorfeshan, S. M. Mousavi, V. Mohagheghi, and B. Vahdani, "Selecting project-critical path by a new interval type-2 fuzzy decision methodology based on MULTIMOORA, MOOSRA AND TPOP methods," Computers \& Industrial Engineering, vol. 120, no. 1, pp. 160-178, 2018.

[11] W. H. Ip, M. Huang, K. L. Yung, and D. Wang, "Genetic algorithm solution for a risk-based partner selection problem in a virtual enterprise," Computers \& Operations Research, vol. 30, no. 2, pp. 213-231, 2003.

[12] C. L. Hwang, K. Yoon, C. L. Hwang et al., "Multiple attribute decision making," Lecture Notes in Economics and Mathematical Systems, vol. 404, no. 4, pp. 287-288, 1981.

[13] T. L. Saaty, "Decision making with the analytic hierarchy process," International Journal of Services Sciences, vol. 1, no. 1, pp. 83-98, 2008.

[14] M. M. Dehcheshmeh, M. Esmaelian, and M. Rabieh, "The robust linear programming technique for multi-dimensional analysis of preferences," International Journal of Information and Decision Sciences, vol. 7, no. 2, pp. 140-165, 2015.

[15] C.-T. Chen, "Extensions of the TOPSIS for group decisionmaking under fuzzy environment," Fuzzy Sets and Systems, vol. 114, no. 1, pp. 1-9, 2000.

[16] A. Serafim and G.-H. Tzeng, "Extended VIKOR method in comparison with outranking methods-scienceDirect," European Journal of Operational Research, vol. 178, no. 2, pp. 514-529, 2007.

[17] K. P. Yoon and C. L. Hwang, "Multiple attribute decision making: an introduction," Sage, vol. 104, 1995.

[18] A. Hadi-Vencheh and M. Mirjaberi, "Fuzzy inferior ratio method for multiple attribute decision making problems," Information Sciences, vol. 277, pp. 263-272, 2014. 
[19] J.-K. Chen and I.-S. Chen, "Using a novel conjunctive MCDM approach based on DEMATEL, fuzzy ANP, and TOPSIS as an innovation support system for Taiwanese higher education," Expert Systems with Applications, vol. 37, no. 3, pp. 1981-1990, 2010.

[20] S. Opricovic and G.-H. Tzeng, "Compromise solution by MCDM methods: a comparative analysis of VIKOR and TOPSIS," European Journal of Operational Research, vol. 156, no. 2, pp. 445-455, 2004.

[21] A. Tversky and D. Kahneman, "Advances in prospect theory: cumulative representation of uncertainty," Journal of Risk and Uncertainty, vol. 5, no. 4, pp. 297-323, 1992.

[22] J. M. Zeng, "An experimental test on cumulative prospect theory," Journal of Jinan University (Natural Science \& Medicine Edition), vol. 4, no. 1, pp. 44-47+65, 2007.

[23] M. A. Jian and X. Sun, "Modified value function in prospect theory based on utility curve," Information and Control, vol. 40, no. 4, pp. 501-506, 2011.

[24] J. W. Gao and F. J. Guo, "Intuitionistic fuzzy stochastic multicriteria decision-making method based on modified prospect theory," Control and Decision, vol. 34, no. 2, pp. 317-324, 2019.

[25] Y. M. Wang, C. P. Que, and Y. X. Lan, "Hesitant fuzzy TOPSIS multi-attribute decision method based on prospect theory," Control and Decision, vol. 32, no. 5, pp. 864-870, 2017.

[26] Y. Liu, J. Forrest, S. F. Liu et al., "Multi-objective grey target decision-making based on prospect theory," Control and Decision, vol. 28, no. 3, pp. 345-350, 2013.

[27] M. Brendel, Die passenden Werkzeuge und Partner für den Bau eines CRM-Gebäudes, Gabler Verlag, Wiesbaden, Germany, 2003.

[28] K. D. Brouthers, L. E. Brouthers, and T. J. Wilkinson, "Strategic alliances: choose your partners," Long Range Planning, vol. 28, no. 3, pp. 18-25, 1995.

[29] M. T. Dacin, M. A. Hitt, and E. Levitas, "Selecting partners for successful international alliances: examination of U.S. and Korean firms," Journal of World Business, vol. 32, no. 1, pp. 3-16, 1997.

[30] Y. Y. Chen, G. F. Farris, and Y. H. Chen, "Effects of technology cycles on strategic alliances," International Journal of Technology Management, vol. 53, pp. 121-148, 2015.

[31] W. Y. Wu, H. A. Shih, and H. C. Chan, "The analytic network process for partner selection criteria in strategic alliances," Expert Systems with Applications, vol. 36, pp. 4646-4653, 2009.

[32] R. Angeles and R. Nath, “An empirical study of EDI trading partner selection criteria in customer-supplier relationships," Information \& Management, vol. 37, no. 5, pp. 241-255, 2000.

[33] M. Z. Solesvik and P. Westhead, "Partner selection for strategic alliances: case study insights from the maritime industry," Industrial Management \& Data Systems, vol. 110, no. 5-6, pp. 841-860, 2010.

[34] Y. Y. Kor and A. Mesko, "Dynamic managerial capabilities: configuration and orchestration of top executives' capabilities and the firm's dominant logic," Strategic Management Journal, vol. 34, no. 2, pp. 233-244, 2013.

[35] J. Guan and N. Ma, "Innovative capability and export performance of Chinese firms," Technovation, vol. 23, no. 9, pp. 737-747, 2003.

[36] C. E. Helfat, "Know-how and asset complementarity and dynamic capability accumulation: the case of r\&d," Strategic Management Journal, vol. 18, no. 5, pp. 339-360, 1997.

[37] C. E. Helfat and M. A. Peteraf, "Managerial cognitive capabilities and the microfoundations of dynamic capabilities,"
Strategic Management Journal, vol. 36, no. 6, pp. 831-850, 2015.

[38] X. Tan, "Clean technology R\&D and innovation in emerging countries-Experience from China," Energy Policy, vol. 38, no. 6, pp. 2916-2926, 2010.

[39] P. Y. K. Chau and F.-R. Lin, "Special section: service innovation in E-commerce," Electronic Commerce Research and Applications, vol. 10, no. 1, pp. 4-5, 2011.

[40] A. Çelen, "Comparative analysis of normalization procedures in TOPSIS method: with an application to Turkish deposit banking market," Informatica, vol. 25, no. 2, pp. 185-208, 2014.

[41] M. El Alaoui, H. Ben-Azza, and K. El Yassini, "Fuzzy TOPSIS with coherent measure: applied to a closed loop agriculture supply chain," Advances in Intelligent Systems and Computing, vol. 1, pp. 106-117, 2019.

[42] M. E. Alaoui, Fuzzy TOPSIS: Logic, Approaches, and Case Studies, CRC press: Taylor \& Francis Group, Boca Raton, FL, USA, 2021.

[43] N. Ploskas and J. Papathanasiou, "A decision support system for multiple criteria alternative ranking using TOPSIS and VIKOR in fuzzy and nonfuzzy environments," Fuzzy Sets and Systems, vol. 377, pp. 1-30, 2019.

[44] C.-T. Chen, C.-T. Lin, and S.-F. Huang, "A fuzzy approach for supplier evaluation and selection in supply chain management," International Journal of Production Economics, vol. 102, no. 2, pp. 289-301, 2006.

[45] E. C. Pérez, M. T. Lamata, and J. L. Verdegay, "RIM-reference ideal method in multicriteria decision making," Information Sciences, vol. 337, pp. 1-10, 2016.

[46] Garcia, A General Model for Linear Programming with Interval Type-2 Fuzzy Technological Coefficients, Fuzzy Information Processing Society, Fortaleza, Brazil, 2012.

[47] K. Mukherjee, "Analytic hierarchy process and technique for order preference by similarity to ideal solution: a bibliometric analysis "from" past, present and future of AHP and TOPSIS," International Journal of Intelligent Engineering Informatics, vol. 2, no. 2/3, pp. 96-117, 2014.

[48] R. F. D. F. Aires and L. Ferreira, "The rank reversal problem in multi-criteria decision making: a literature review," Pesquisa Operacional, vol. 38, no. 2, pp. 331-362, 2018.

[49] A. Rfdfa and B. Lf, "A new approach to avoid rank reversal cases in the TOPSIS method," Computers \& Industrial Engineering, vol. 132, pp. 84-97, 2019.

[50] T. Arslan, "A weighted euclidean distance based TOPSIS method for modeling public subjective judgments," AsiaPacific Journal of Operational Research, vol. 34, no. 3, Article ID 1750004, 2017. 